\title{
Synthesis and Wear Characterization of Ultrasonic Electrodeposited Ni-TiN Thin Coatings
}

\author{
Tianxiang Liu ${ }^{1}$, Chaoyu $\mathrm{Li}^{2}$, Qiang $\mathrm{Li}^{2}$, Liangzhao Li ${ }^{3}$, Fafeng Xia ${ }^{2}$, Haiyan Xing ${ }^{2 *}$, Chunyang $\mathrm{Ma}^{2}$ \\ ${ }^{1}$ College of Engineering, Heilongjiang Bayi Agricultural University, Daqing 163319, China; \\ ${ }^{2}$ College of Mechanical Science and Engineering, Northeast Petroleum University, Daqing 163318, \\ China; \\ ${ }^{3}$ School of Chemistry \& Environmental Engineering, Hanshan Normal University, Chaozhou 521041, \\ China \\ *E-mail: chunyangandma1@163.com
}

doi: $10.20964 / 2021.01 .50$

Received: 1 October 2020 / Accepted: 12 November 2020 / Published: 30 November 2020

\begin{abstract}
This work describes the use of a modified Watt nickel bath to prepare pure $\mathrm{Ni}$ and $\mathrm{Ni}$-TiN thin coatings by the application of ultrasonic electrodeposition (UE) under pulse current (PC) conditions. X-ray diffraction (XRD), transmission electron microscopy (TEM), scanning electron microscopy (SEM), scanning probe microscopy (SPM) were used to investigate the influences of ultrasonic intensity on phase composition, surface topography, and microscopic structure. The Vickers hardness, wear resistance of $\mathrm{Ni}$ and $\mathrm{Ni}-\mathrm{TiN}$ coatings, and coefficient of friction were also tested. The TEM, SEM, and SPM results showed that under the ultrasonic wave with the intensity of $30 \mathrm{~W} / \mathrm{cm}^{2}$, Ni-TiN coatings exhibited a glossy and uniform surface topography. For NT-2 coating with a superficial area of 4.102 $\mu \mathrm{m}^{2}$, the root means square $(R m s)$ roughness was $36.825 \mathrm{~nm}$ and the arithmetic mean roughness $(R a)$ was $22.658 \mathrm{~nm}$. The average size of $\mathrm{Ni}$ grains was $47.1 \mathrm{~nm}$, whereas that of TiN nanoparticles was observed as $23.2 \mathrm{~nm}$. The diffraction angle of the coatings with disparate coating parameters in the XRD analysis was found to be similar to the Ni phase, however, the intensity of diffraction varied. The microhardness experiment showed that the minimum microhardness of the Ni film was $387.6 \mathrm{HV}$. Furthermore, the maximum microhardness value got from the Ni-TiN coating under the ultrasonic wave with an intensity of $30 \mathrm{~W} / \mathrm{cm}^{2}$ was $912.1 \mathrm{HV}$. Wear and friction evaluation showed that the loss in weight of Ni-TiN coatings performed with $30 \mathrm{w} / \mathrm{cm}^{2}$ ultrasonic intensity was the smallest, and the average friction coefficient was measured to be 0.39 , thus exhibiting good resistance to wear.
\end{abstract}

Keywords: Preparation; 3D surface morphology, Ni-TiN thin coating; Microstructure, Wear assessment 
(C) 2021 The Authors. Published by ESG (www.electrochemsci.org). This article is an open access article distributed under the terms and conditions of the Creative Commons Attribution license (http://creativecommons.org/licenses/by/4.0/). 